\title{
Phytochemical Screening and Nanosynthesis of Linum usitatissimum [Flax seeds] used in Hypothyroid Treatment
}

\author{
NAMITA BHARADWAJ' and NAVED SIDDIQUI ${ }^{1 *}$ \\ Department of Chemistry, Dr C. V. Raman Univercity, Bilaspur Chhattisgarh, India. \\ ${ }^{\star}$ Corresponding author E-mail naved8333@gmail.com \\ http://dx.doi.org/10.13005/ojc/370332
}

(Received: March 22, 2021; Accepted: May 17, 2021)

\begin{abstract}
Medicinal plants are the richest biosource of drugs of traditional system of medicine. Flax seeds (Linum usitastassimum $L$ ) is a multipurpose crop and its consumption is beneficial for health. Flax seeds is a abundant spring of healthy fat, antioxidant and fibre. The nutrient in flax seeds may help under risk of diabetes, cancer, cardiac disease and thyroid. The present study deals with qualitatitive analysis of phytochemicals by the standard method of Harbone, followed by the extraction of seed oil by soxhlet apparatus using petroleum ether as solvent. Quantitative analysis were also done to determine the amount of such phytochemicals. Phytochemicals analysis of flax seeds showed the presence of glycosides,alkaloids and flavonoids in varying amounts which can be used in future for preparation of herbal drugs. Nanosynthesis of flax seeds were also done by using silver nitrate and silver nanoparticle. Characterisation of silver nanoparticle by UV-Spectroscopy, SEM and EDX analysis And FTIR Analysis.
\end{abstract}

Keywords: Linum usitassimum L, Flavonoids, Alkaloids, Glycosides, Nanosynthesis.

\section{INTRODUCTION}

The thyroid is a small butterfly-shaped gland is positioned in front of neck, just below the voice box (larynx). This gland plays a completely important role in controlling our frame metabolism i.e The rate at which our frame uses electricity and it does this through producing thyroid hormones like thyroxin or T4 and Triode thyronine or T3, chemical compounds that travel through our blood to every components of our body. It produces chemical compounds that help the frame to control metabolism. Thyroid hormone is commonly produced in response to every other hormone launched via the pituitary gland. ${ }^{1}$ Generally, thyroid troubles are grouped in two most important classes i.e Hyperthyroidism (too much thyroid hormone) and hypothyroidism, (too little thyroid hormone) right here we discuss approximately hypothyroidism, the most not unusual signs of hypothyroidism includes fatigue, depression, constipation, weight advantage, gradual coronary heart rate and so forth. Medicinal plants are the richest bio-resources of medication for classic device of medicine. Flax seeds (Linum usitastassimum $\mathrm{L}$ ) is a multipurpose crop and its intake is beneficial for fitness. ${ }^{2}$ Flax seeds is a wealthy supply of healthy fats, antioxidant and fibre.

This is an Open Access article licensed under a Creative Commons license: Attribution 4.0 International (CC- BY). Published by Oriental Scientific Publishing Company @ 2018

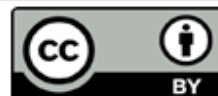


The nutrient in flax seeds may additionally assist decrease danger of diabetes, most cancers, heart ailment and thyroid ${ }^{3}$. Flax seeds is one of the oldest vegetation, having been cultivated due to the fact the beginning of civilization. The Latin name of the flax seed is Linum usitatissimum, which means very beneficial. Flax seed is one of the high content of omega-three fatty acids ie. Alpha linolinic acid $(\mathrm{ALA})^{4}$ and liganans (phytoestrogens).

The crucial flax seeds developing international locations are Canada, China, U.S, India and Ethiopia.

Flax seeds has potential health benefits besides the nutrition, due to mainly three reason; Firstly due to rich source of omega-3-linolenic acid. Secondly being rich in dietary soluble and insoluble fibres and third, due to its high contents of liganins, acting as antioxidants, phytoestrogens ${ }^{5}$. The healthy use of all the three omega-3 fatty acids have been mostly indicated in several conditions like cardiac diseases, hypertension, diabetic condition osteoporosis and in many autoimmune conditions and neurological disorders ${ }^{6}$. The medicinal importance of a plant is due to the presence of some specific material like alkaloids, glycosides, resins, volatile oil, gum and tannins etc. Considering all these valuable points the present study is designed to investigate the presence of various phytochemicals in the flax seeds ${ }^{7}$. In todays condition $\mathrm{AgNO}_{3}$ can be prepared by different methods like biologically or chemically. These nanoparticle are of prominent use in many fields like industrial, pharmaceutical, and medicinal field.

In the present work, the silver nanoparticles were prepared from the flax seeds extract and it is characterized by UV-Vis spectroscopy, Sem analysis with EDX and FTIR analysis.

\section{MATERIAL AND METHOD}

\section{Collection of seeds}

The seeds of flax were accumulated from local market of Bilaspur (C.G) India.

\section{Extraction of seeds oil}

The seeds were nicely wiped clean and air dried. The dried sample had been then powdered with the assist of house keep grinder. The powdered pattern became stored in an air tight box. Extraction of seeds oil is accomplished by using using sohxlet apparatus the use of petroleum ether as solvent. The extract obtained become gathered and filter via Wattmann No.1 clear out paper to take away alldebris and unextracted count number. Filtered extract become concentrated the usage of rotatary evaporator at 40 diploma centigrade to acquire focused extract ${ }^{8}$.

\section{Phytochemical screening of Flax seeds}

Qualitative and quantitative evaluation of flax seeds were finished by way of using general strategies.

\section{Qualitative analysis of phytochemicals in flax seeds}

Chemical test are performed by using standard method of Harborn, $1984 .^{9}$

\section{Quantitative Analysis of flax seeds}

Quantitative check had been accomplished by way of using standard technique of Harborn 1973. ${ }^{10,11,12}$

\section{Chromatography Analysis}

Preparation for TLC analysis-Small quantity of seed powder $(25 \mathrm{mg}$ ) have been dissolved in $1 \mathrm{~mL}$ methanol. Different mobile section at distinctive percentage were taken for the analysis. In case of flax seeds unique cellular solvent gadget have been taken for Preparing take a look at :-According to Harborne ${ }^{10}$ by means of the usage of to separation solvent and the lignan was appeared as dark spot on TLC plate as shown in Fig. 1. Various separation solutions like (ethyl acetate: Water) in ratio (1:19) and (Benzene: Methanol) in ratio (1:9). The dark spot has Rf: 0.45 and this $R f$ value is equal to $R f$ value of lignin, according to Harborn[7], when used the liquid-liquid system to separate the lignan from flaxseed. The ethyl acetate: water system has weak polarity and the lignan is soluble in water and when we evaporate water yellowish powder is obtained ${ }^{13}$

\section{Nanosynthesis}

In present world, nanotechnology a moderately new field, Nano, a logical word is utilized for deciding the size of the molecule ${ }^{14}$ Nanosynthesis, an idea in the field of research and innovation, lately, has likewise been probably going to become dependent on their interest, as different advances. 
Nanoparticles are normally a bunch of atoms running between 1-100 $\mathrm{nm}$ in and they display new properties dependent on their size, conveyance \& morphology ${ }^{15}$. Numerous materials are combined in nano size for different uses including medical field, scientist in the field of nanotechnology are finding that metals nanoparticles have a wide range of surprising advantages. They are normally set up by honorable metals, that is, $\mathrm{Ag}, \mathrm{Au}$, pt and pd while silver nanoparticles (AgNPs) are mostly exploited ${ }^{16}$ due to its more extensive scope of use in medication, hardware, energy saving, climate, material, beautifiers, biomedical, and so forth.

\section{Preparation of aq.AgNO}

$\mathrm{AgNO}_{3}$ solution $(1 \mathrm{mM})$ is prepared and saved in dark coloured bottles.

\section{Synthesis of AgNPs}

Seeds extract of 1 to $5 \mathrm{~mL}$ have been taken separately and in this extract $10 \mathrm{~mL}$ of $1 \mathrm{mM} \mathrm{AgNO}_{3}$ solution become delivered with steady stirring and exposed to one of a kind situations like sunlight irradiation, UV-irradiation. The colour change of the solution was periodically checked. The colour exchange of the seed extract from light yellow to dark brown indicates that the AgNPs have been prepared from seeds extract. This nanoparticle extract are subjected to centrifugation at 10,000 rpm for 15 minute. The pellet prepared were treated with 0.1 $\mathrm{mL}$ of toluene $\mathrm{H}_{2} \mathrm{O}$ and dried in air.

\section{Characterisation of silver nano particles UV-spectrophotometer}

The prepared AgNPs were checked by estimating the UV-Vis range of the decrease media in the wake of weakening a little aliquot of the example in distilled water. UV-spectroscopy was done on Systronics UV-noticeable spectrophotometer and checking the spectra between $200-700 \mathrm{~nm}$ at the goal of $1 \mathrm{~nm}^{17}$

\section{SEM and EDAX examination}

Scanning electron Microscopic (SEM) investigation was finished utilizing ZEISS EVO 18 special ${ }^{18}$. Edition machine additional arrangement was eliminated utilizing smudging paper and afterward films on SEM matrix were permitted to dry by putting it under mercury light for 5 minutes.

\section{FTIR ANALYSIS}

In (FT-IR) Technique Fourier transform infrared (FTIR) spectrophotometer is used to detect functional groups involved in synthesis of nanoparticle at and this study were carried out in the flaxseed hydroalcoholic extract. Fig. 6 shows FT-IR spectra of flaxseed hydroalcoholic extract. The result of FTIR analysis of this work show various bond streaching at different peak. 2923.89 for $\mathrm{OH}$ streaching peaks and 2853.8 for $\mathrm{C}-\mathrm{H}$ peaks resp. The peak 1740.86 correspond to $\mathrm{C}=\mathrm{C}$ stretching (non conjugated). The peak 1460.51 refers to $\mathrm{C}-\mathrm{H}$ bending. The peak 1374.20 corresponds $\mathrm{C}-\mathrm{H}$ bending. 1236.87 corresponds to $-\mathrm{OH}$ group. 1159.89 correspond to carboxlic acids. 1098.24 streching is correspond to $\mathrm{C}-\mathrm{O}$ group. The peak 971.85 corresponds to C-group.The peak 722.14 streching is correspond to $>\mathrm{COOH}$ group. ${ }^{19}$

\section{RESULT AND DISCUSSION}

In the present study qualitative analysis of flax seeds shows the presence of alkaloids, phenolic compounds, carbohydrates, proteins, amino acid, flavonoids, saponins are present in extract of flax seeds while terpenoids is absent in extract of flax seeds. Quantitative analysis of flax seeds shows alkaloids $0.16 \mathrm{mg}$, saponins $0.41 \mathrm{mg}$, phenols $0.23 \mathrm{mg}$, flavonoids $0.17 \mathrm{mg}$, carbohydrate $0.49 \mathrm{mg}$ of phytochemicals. Due to presence of these phytochemicals the importance of flax seeds in medicinal field increasing day by day.

Table 1: Qualitatative analysis of flax seeds
extract

Table 2: $Q$ uatitative analysis of flax seeds extract

\begin{tabular}{ll}
\hline Alkaloids & $0.16 \mathrm{mg}$ \\
Saponins & $0.41 \mathrm{mg}$ \\
Total phenols & $0.23 \mathrm{mg}$ \\
Flavonoids & $0.71 \mathrm{mg}$ \\
Carbohydrates & $0.49 \mathrm{mg}$ \\
\hline
\end{tabular}

\section{Chromatographic analysis}

TLC is a very simple, lowexpensive and fast method which is mostly used for a qualitative determination of seed extracts and for determining various stages of lignin seperation. The lignan compound has Rf-0.45 and this equal to $\mathrm{Rf}$ value according to Harborne ${ }^{10}$. 

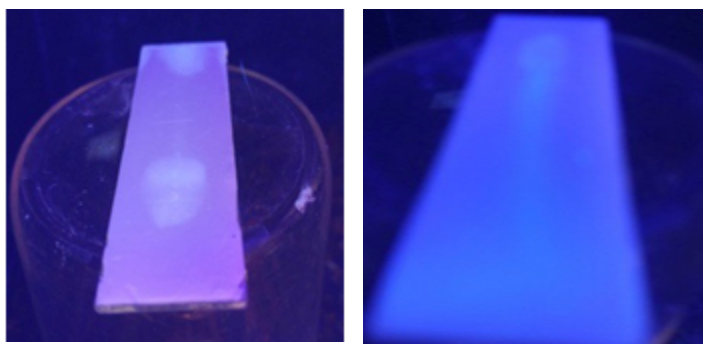

Fig. 1. TLC chomatography

\section{Nanosynthesis}

Silver nano particle were prepared by using silver nitrate solution of $1 \mathrm{nM}$ through nanosynthesis and colour change were observed from light yellow to dark brown by continous stirring in magnetic stirrer for $30 \mathrm{~min}$ at high temperature.

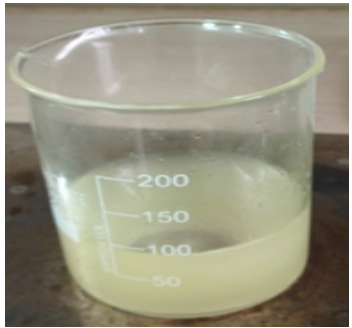

Before

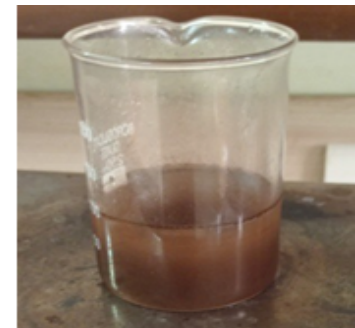

After
Fig. 2. Nanosynthesis of flax seeds

After nanosynthesis of seeds extract characterisation of nanoparticle were conducted through different instrumental methods. Like UV-spectroscopy in this analysis absorption band is 348 is observed.

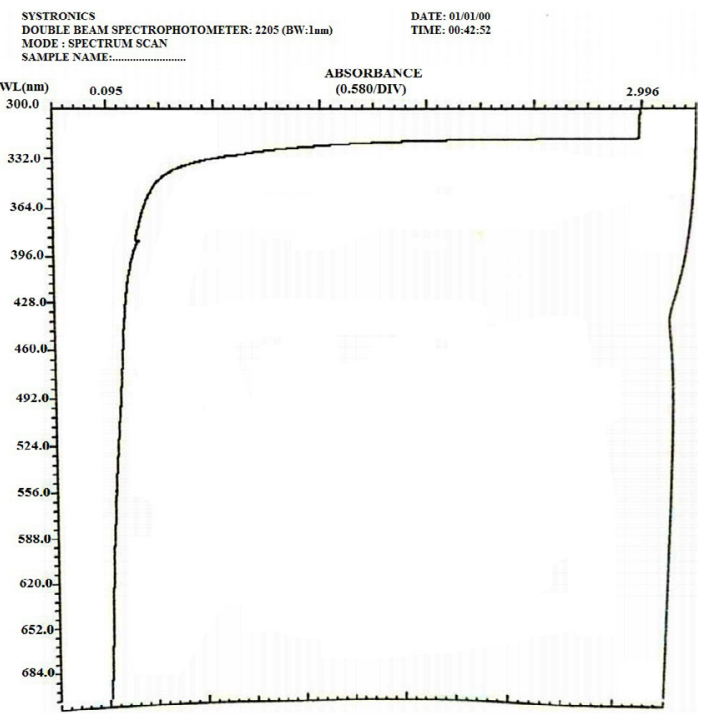

Fig. 3. Graph of UV-Visible Spectrophotometer

\section{SEM and EDX analysis}

The results of SEM analysis Fig. 4. show that the synthesized silver nanoparticles are of evenly distributed size and spherical in shape. Thus, the Ag nano-particles are on evenly distributed throughout the process and also the size and stability of nanoparticles are uniform on the process. The results of EDX helps in determining the elemental composition of the AgNPs Fig. 5. This analysis helps in confirmation of the presence of the AgNPs in the sample on a varying range between $65-78 \mathrm{~nm}$.
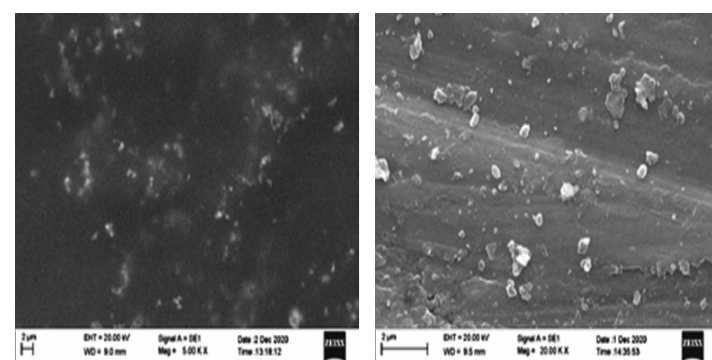

Fig. 4. Sem analysis of nanoparticle of flax seeds

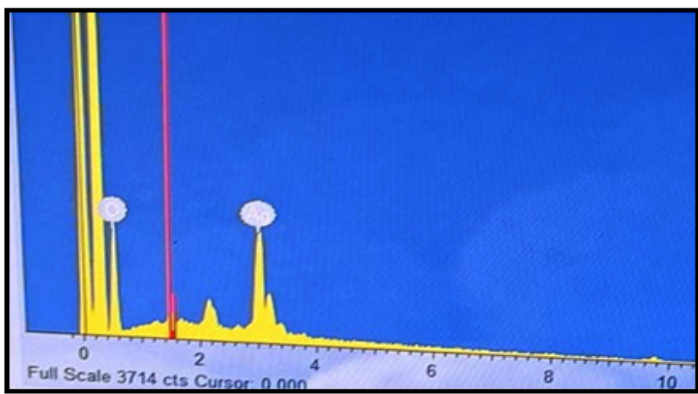

Fig. 5. EDX analysis of nanoparticle of flax seeds

In present work the result of FTIR analysis show different bond streaching at different peaks like 2923.89 and 2853.85 refers to $-\mathrm{OH}$ stretching and $\mathrm{C}-\mathrm{H}$ stretching resp. The peak 1740.86 correspond to $\mathrm{C}=\mathrm{C}$ stretching (non conjugated). The peak 1460.51 corresponds to $\mathrm{C}-\mathrm{H}$ bending. The peak 1374.20 corresponds $\mathrm{C}-\mathrm{H}$ bending. 1236.87 corresponds to $-\mathrm{OH}$ group. 1159.89 correspond to carboxlic acids. 1098.24 streching is correspond to C-O group. The peak 971.85 corresponds to C-group. The peak 722.14 streching is correspond to $>\mathrm{COOH}$ group ${ }^{18}$.

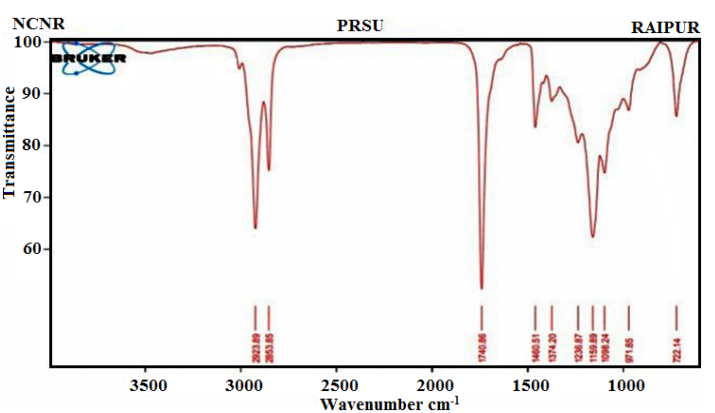

Fig. 6. FTIR analysis of nanoparticle of flax seeds 


\section{CONCLUSION}

The conducted studies concluded that the presence of various secondary metabolites in flaxseeds extract having medicinal properties and because of their natural properties and enhance qualities by nanosynthesis. It will be beneficial to supplement other medical treatment with natural herbs for underactive thyroids. The conducted studies confirms the presence of functional group that form the part of active compounds of flax seeds which have medicinal properties and can be used as antithyroid agents. Flax seeds extract consist of oil in abundance. The active compound in flax seeds is called Omega -3- fatty acids i.e. Alpha linolinic acid has the power to influence thyroid function and improve the condition of hypothyroidism. It has been reported that the consumption of Omega -3dietery supplements leads to significant reduction of non steroidal anti inflammatory drugs. ${ }^{19}$ Studies have shown that the high intake of dietery fibers is beneficial of obesity in both men and women. ${ }^{20}$ An advantage of this herb is decrease the level of harmful cholesterol which is due to high weight gain and which is one of the feature of hypothyroidism.

\section{ACKNOWLEDGEMENT}

The authors would like to acknowledge to Dr. C.V.Raman University for their laboratories facilities and the authors extend their indebted thanks to metallurgy department of NIT Raipur and Pt. Ravi Shanker University Raipur for instrumental analysis.

\section{Conflict of Interest}

There is no conflict of interest among the authors regarding the publication of this manuscript.

\section{REFERENCES}

1. Openheimer, Jack. Molecular Basis of Thyroid Hormone Action, ISBN: 9780124/44279., 2012.

2. Preedy, Victor R.; Watson Ronald, The UShaped curve Book Of lodine intake thyroid Disorder, Comprehensive Handbook of lodine., 2009. 449-455.

3. Guyton, Arthur Clifton; john Hall, Text book of medical physiology 11 ed.ISBN 978143700602., 2005.

4. Veronique $\mathrm{J}$ Barthet., "antioxidant activity of flax seeds meal component, paper No.1074 of the grain reachearch laboratory." Canadian reachearch of plant science., 2014.

5. Simopoulos AP." The importance of the ratio of omega -6 and omega -3 essential fatty acids.'. Biomedicine and pharmacotherapy 2002, 365-379.

6. Amita pandey.; Shalini tripathy.; concept of standardisation, extraction and pre phytochemical screening strategies for herbal drug. Journal of pharmacognosy and phytochemistry., 2014, 2(5), 115-119.

7. R. Nair.; S.H. Varghese.; B.G. Nair.; T. Maekawa.; Y. Yoshida and D.S. Kumar, "Nanoparticulate material delivery to plants,"
Plant Science., 2010, 179, 154-163.

8. Nikhal SB.; Dambe PA.; Ghongade DB.; Goupale DC. Hydroalcoholic extraction of Mangifera indica (leaves) by Soxhletion. International Journal of Pharmaceutical Sciences., 2010, 2(1), 30-32.

9. Harborne J B phytochemical methods; A guide to modern technique of plant analysis sec edision., 1984, 37-175.

10. Harborne JB, Phytochemical methods, Aguide to mo dern techniques of plant analysis. Chapman and Hall, London., 1973. ISBN 978-0-412-57260-9.

11. Krishnaswami. D.; T. Devi<A Bono and R. Sarbatly, studies on phytochemical constituents of six malaysium plants., 2009 3(2), 67-72.

12. Krishnavami.; S B Theymoli.; S, Sadasivam, phenol sulphuric acid method, Food Chain., 1984, 15-229.

13. Paul MD, and David EJ., Phytochemistry., 1981, 20(9), 2277-228013

14. Albrecht MA.; Evans CW.; Raston CL Green chemistry and the health implications of nanoparticles. Green Chem., 2006, 8, 417432. Edition machine. 
15. K. Satyavani.; T. Ramanathan and S. Gurudeeban, Plant Mediated Synthesis of Biomedical Silver Nanoparticles by Using Leaf Extract of Citrullus colocynthis. Research $J$. Nanoscie and Nanotech., 2011, 1, 95-101.

16. Roy N.; Barik A Green synthesis of silver nanoparticles from the unexploited weed resources. Int J Nanotechnol Appl., 2010, 4, 95-101.

17. Metha, Akul 22 April (2012). "Derivation of Beer-Lambert Law". PharmaXChange.info.^ Misra, Prabhakar; Dubinskii, Mark, eds. Ultraviolet Spectroscopy and UV Lasers. New York: Marcel Dekker. ISBN 978-0-82470668-5., 2002.

18. M. F. Khan.; M. Hameedullah.; A. H. Ansari.; E.
Ahmad.; M. Lohani.; R. H. Khan.; M. M. Alam.; W. Khan.; F. M. Husain and I. Ahmad, Int. J. Nanomed., 2014, 9, 853.

19. Ragavendran P.; Sophia D.; Arul Raj C.; Gopalakrishnan VK. Functional group analysis of various extracts of Aerva lanata (L.,) by FTIR spectrum. Pharmacology online., 2011, 1, 358-64.

20. Arend wp.; Dayer JM.; Inhibition of the production and effect of interlukin-1 tumornecrosis factor in rheumatoid arthritis 1995, 38, 51-166.

21. Du H, Dietery fiber and subsequent changes in body weight and waist circumference in European men and women $A M J$ clinical nutrition 2010, 91, 329-331. 